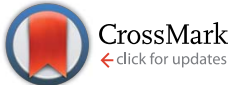

Cite this: RSC Adv., 2016, 6, 96355

Received 28th July 2016

Accepted 22nd September 2016

DOI: 10.1039/c6ra19111h

www.rsc.org/advances

\section{Mangifera indica, Ficus religiosa and Polyalthia longifolia leaf extract-assisted green synthesis of graphene for transparent highly conductive film $\dagger$}

\begin{abstract}
Pankaj Chamoli, ${ }^{a}$ Raghunandan Sharma, ${ }^{b}$ Malay K. Das ${ }^{\text {b }}$ and Kamal K. Kar*ab
A green approach to synthesize graphene nanosheets (Gns) by reduction of graphene oxide (GO) using Mangifera indica, Ficus religiosa or Polyalthia longifolia leaf extract as reducing agent has been demonstrated. Further, transparent conducting films (TCFs) have been fabricated by spray coating of the synthesized Gns and the optoelectrical properties of the TCFs have been investigated. Of the three leaf extracts, Mangifera indica offers the best alternative reducing agent for the green synthesis of Gns at large scale. Raman spectroscopy reveals that GO has been deoxygenated significantly, with a Raman D to $G$ band intensity ratio of $\sim 1.21$, while the attainment of a C/O ratio of $\sim 4.58$ in the synthesized Gns has been confirmed by elemental analysis. The TCF fabricated after thermal graphitization $\left(900{ }^{\circ} \mathrm{C}\right.$ for 1 h) of the spray coated Gns film shows a sheet resistance of $\sim 2.08 \mathrm{k} \Omega \square^{-1}$ and transmittance of $\sim 57.31 \%$ at $550 \mathrm{~nm}$. The study suggests significant potential for the application of plant leaf extracts as non-toxic reducing agents in large-scale production of Gns. Apart from providing an alternative to hazardous reducing agents, this approach opens the possibility of preparation of Gns at large scale by using more accessible natural resources with mild synthesis conditions.
\end{abstract}

\section{Introduction}

Graphene, a flat monolayer of $\mathrm{sp}^{2}$ hybridized carbon arranged in a honeycomb lattice, has received great attention in the scientific community around the globe owing to its outstanding properties such as excellent room temperature carrier mobility $\sim 200000 \mathrm{~cm}^{2} \mathrm{~V}^{-1} \mathrm{~s}^{-1}$, high optical transmittance $\sim 97.7 \%$, fracture strength $\sim 130 \mathrm{GPa}$ and excellent thermal conductivity $\sim 5000 \mathrm{~W} \mathrm{~m}^{-1} \mathrm{~K}^{-1}$; and it has opened broad areas of research in nanoscience and technology. ${ }^{1}$ Graphene has $2 \mathrm{D}$ planar structure and is a basic building block for all graphitic materials including fullerenes (0D), carbon nanotubes (1D), and graphite (3D), from nanoscale to bulk. The remarkable properties of graphene have potential application in modern electronic devices such as touch screens, displays, thin-film transistors, thin film photovoltaics and flexible electronics; and in various biomedical applications such as tissue engineering, drug delivery and bio-imaging. ${ }^{2-8}$ Several methods, including chemical vapor deposition (CVD), arc discharge, monolayer or bilayer extraction from exfoliated graphite, wet chemical route via

${ }^{a}$ Advanced Nanoengineering Materials Laboratory, Materials Science Programme, Indian Institute of Technology Kanpur, Kanpur - 208016, India

${ }^{b}$ Advanced Nanoengineering Materials Laboratory, Department of Mechanical Engineering, Indian Institute of Technology Kanpur, Kanpur - 208016, India. E-mail: kamalkk@iitk.ac.in; Fax: +91-512-2597408; Tel: +91-512-2597687

$\uparrow$ Electronic supplementary information (ESI) available. See DOI: 10.1039/c6ra19111h chemical reduction of graphene oxide (GO), etc., have been employed for synthesis of graphene nanosheets (Gns). ${ }^{9-16}$ Among these, wet chemical routes are the most versatile and cost effective. In this process, Gns are produced by chemical reduction of GO in the presence of a reducing agent such as hydrazine and its derivatives, sodium borohydride, ${ }^{12}$ hydroquinone, ${ }^{13}$ hydroiodic acid/acetic acid, ${ }^{\mathbf{1 4 , 1 5}}$ polyethyleneimine, ${ }^{\mathbf{1 6}}$ etc.

However, application of such toxic reducing agents for largescale production is hazardous for human health as well as for the ecosystem. To minimize the environmental impacts, natural/non-toxic reducing agents such as melatonin, vitamin $\mathrm{C}$, sugar, etc. have been investigated as reducing agents for GO reduction. ${ }^{17}$ In addition, plant extracts consisting of different biomolecules, including proteins, amino acids, enzymes, vitamins, etc., are being considered as easily accessible, cost efficient and environmentally friendly sources of reducing agents for reduction of GO. ${ }^{18-20}$ Especially, leaf extracts of Colocasia esculenta, ${ }^{18,19}$ Mesua ferrea Linn., ${ }^{18}$ Tamarix gallica, ${ }^{20}$ etc. have been explored for their ability to reduce GO. However, owing to the low concentration and poor activity of such plant extracts, the GO reduction process is time consuming and inefficient. Hence, exploring other plants with high concentrations of phytochemicals with reducing properties is of significant importance towards providing green alternatives for reduction of GO. Ficus religiosa, Mangifera indica, and Polyalthia longifolia leaves, which have had sacred importance in Hindu mythology from ancient times in India, exhibit several pharmacological 
activities owing to their anti-inflammatory, anti-oxidant, antiallergic and anthelmintic properties. ${ }^{21,22}$ Mangifera indica leaves, especially, show excellent anti-oxidant activity owing to the presence of the phenolic compounds such as mangiferin (a special xanthone termed a "super-anti-oxidant") and quercetin, which have been widely studied for their pharmacological properties. $^{23,24}$ Hence, these leaf extracts may provide green alternatives to replace the toxic reducing agents for reduction of GO.

On the other hand, modern devices such as touch screens, displays, organic light-emitting diodes (OLEDs) and photovoltaic cells have an essential component, transparent conducting film (TCF) ${ }^{25}$ In particular, graphene-based TCFs may provide a potential alternative to the conventional TCFs based on scarce and costly metals such as indium. ${ }^{26}$ Owing to its low cost, easy processing, and excellent dispersibility in organic solvents such as $N, N$-dimethylformamide (DMF), $N, N$-dimethylacetamide (DMA), and $N$-methyl-2-pyrrolidone (NMP) etc., solution-processed graphene synthesized by chemical reduction of GO has been investigated for TCF applications. ${ }^{27}$ For example, Li et al. have used a layer-bylayer deposition technique with exfoliated graphite in DMF solvent to obtain sheet resistance $\left(R_{\mathrm{s}}\right)$ and transmittance $(T)$ of $\sim 150 \mathrm{k} \Omega \square^{-1}$ and $\sim 92 \%$, respectively, for the fabricated TCFs. $^{28}$ Mattevi et al. have employed a transfer printing technique to fabricate TCFs with $R_{\mathrm{s}}$ of $\sim 3.5 \mathrm{k} \Omega \square^{-1}$ and $T$ of $\sim 85 \% .{ }^{29}$ Similarly, Wu et al. have fabricated TCFs with $R_{\mathrm{s}}$ of $\sim 5 \mathrm{k} \Omega \square^{-1}$ and $T$ of $\sim 80 \%$ by a spin coating technique, ${ }^{30}$ while Zhao et al. have used a dip coating technique to fabricate TCFs with $R_{\mathrm{S}}$ and $T$ of $\sim 8 \mathrm{k} \Omega \square^{-1}$ and $\sim 70 \%$, respectively. ${ }^{31}$ In addition, Sundramoorthy et al. have deposited TCFs by a vacuum filtration technique to attain $R_{\mathrm{s}}$ $\sim 890 \pm 47 \mathrm{k} \Omega \square^{-1}$ and $T \sim 90 \% .^{32}$ Recently, Lux et al. have presented a reliable process to deposit TCFs by a vacuum arc system on silicon oxide, quartz, and sapphire using a solid carbon source and have obtained $R_{\mathrm{s}}$ of $5.7 \mathrm{k} \Omega \square^{-1}$ and $T$ of $88 \% .^{33}$ Apart from these processes, spray coating is an effective technique for the deposition of TCFs of small grain size graphene platelets synthesized by a solution-processable method for better optoelectrical signatures.

Herein, Gns have been synthesized successfully with the help of leaf extracts at the low temperature of $\sim 50{ }^{\circ} \mathrm{C}$. Leaf extracts from three different types of leaves, namely Ficus religiosa, Mangifera indica, and Polyalthia longifolia, have been used for reduction of GO. These are used as green reducing agents owing to their great anti-oxidant properties by virtue of the high content of phenolic compounds. Experimental results show that the maximum reduction occurred for the Mangifera indica leaf extract. This approach has several advantages such as low processing temperature, accessibility of the plant leaves and the non-toxic/environmentally friendly nature of the reducing agents (Table S1; ESI $\dagger$ ). The procedure has been found more suitable for the production of good quality Gns at large scale. The as-synthesized Gns have been characterized by Raman spectroscopy, Fourier transform infrared (FTIR) spectroscopy, thermal gravimetric analysis (TGA), X-ray diffraction (XRD), UVvisible spectroscopy, field emission scanning electron microscopy (FESEM), and X-ray photoelectron spectroscopy (XPS). The synthesized Gns have been used further to fabricate TCFs by a simple spray coating technique (schematically shown in Fig. 1). Finally, optoelectrical properties have been measured after thermal graphitization of the TCFs. The best performing TCF shows a sheet resistance of $\sim 2.08 \mathrm{k} \Omega \square^{-1}$ and a transmittance of $57.31 \%$.

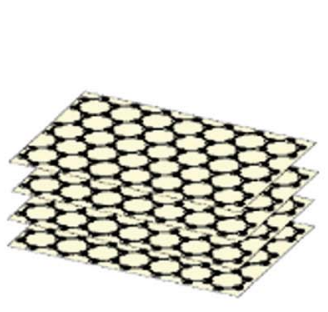

Graphite

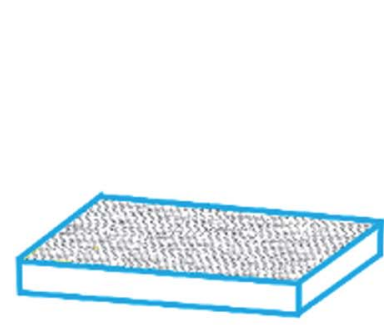

Graphene TCF

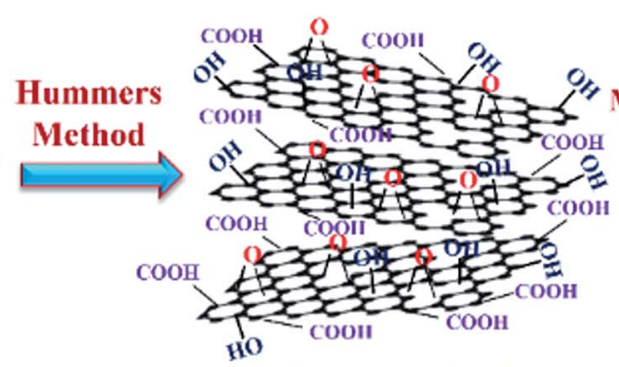

Graphene Oxide

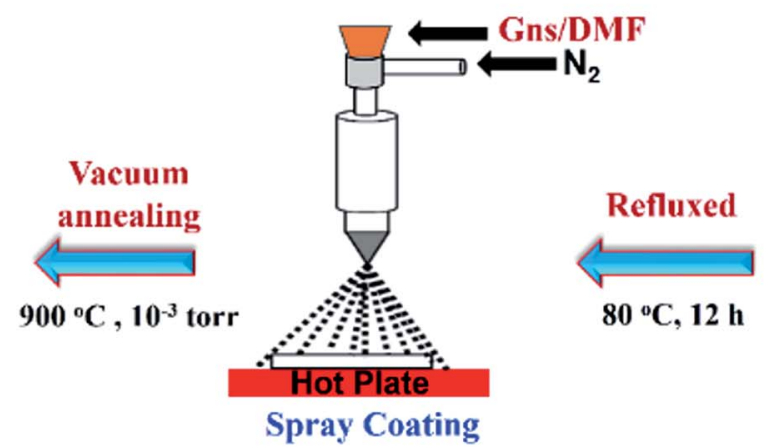

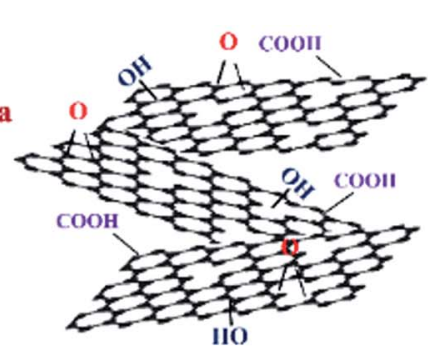

Graphene nanosheets
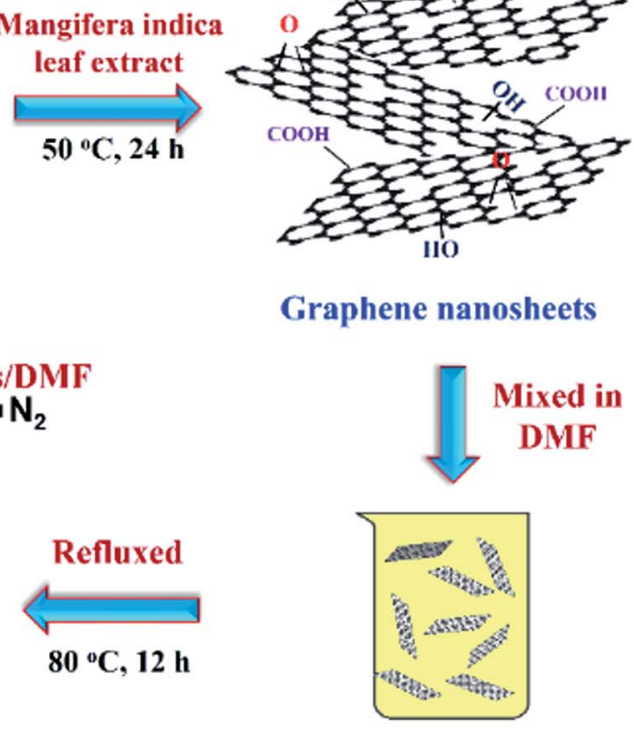

Graphene Dispersion

Fig. 1 Schematic of various steps in the fabrication process of graphene TCF. 


\section{Experimental}

\subsection{Materials}

Three different leaves, i.e., Ficus religiosa, Mangifera indica, and Polyalthia longifolia, were collected from I.I.T. Kanpur campus for leaf extract preparation. Graphite powder obtained from Loba Chemie Pvt Ltd, India, and sulfuric acid $\left(\mathrm{H}_{2} \mathrm{SO}_{4}, 98 \%\right)$, hydrogen peroxide $\left(\mathrm{H}_{2} \mathrm{O}_{2}, 30 \%\right)$, sodium nitrate $\left(\mathrm{NaNO}_{3}\right.$, analytical grade), potassium permanganate $\left(\mathrm{KMnO}_{4}\right.$, analytical grade) and $N, N$ dimethylformamide (DMF) procured from Qualigens Fine Chemicals, India, were used without further purification.

\subsection{Synthesis of GO}

GO was synthesized by a modified Hummers' method as reported elsewhere. ${ }^{34}$ In brief, $\mathrm{H}_{2} \mathrm{SO}_{4}(140 \mathrm{ml}), \mathrm{NaNO}_{3}(2.5 \mathrm{~g})$ and graphite powder $(5 \mathrm{~g})$ were mixed together, with cooling in an ice bath. Further, $\mathrm{KMnO}_{4}(15 \mathrm{~g})$ was added to the mixture, maintaining the temperature below $20{ }^{\circ} \mathrm{C}$ till the mixture changed to green in color. Then, the mixture was shifted to a water bath and again stirred at $35^{\circ} \mathrm{C}$ for $0.5 \mathrm{~h}$. After adding $230 \mathrm{ml}$ of deionized (DI) water dropwise, the mixture was stirred for $0.5 \mathrm{~h}$, then the temperature was raised to $98{ }^{\circ} \mathrm{C}$. Further, DI water $(500 \mathrm{ml})$ and $\mathrm{H}_{2} \mathrm{O}_{2}(50 \mathrm{ml})$ were added until bubble formation stopped, and the mixture was stirred for $0.5 \mathrm{~h}$. Finally, the resultant mixture was allowed to cool at room temperature. The solution was filtered and washed several times with DI water and dried at 60 ${ }^{\circ} \mathrm{C}$ overnight in ambient conditions.

\subsection{Preparation of leaf extract}

Ficus religiosa, Mangifera indica, and Polyalthia longifolia leaves were collected and dried in the shade for 2 weeks before use. Then, $5 \mathrm{~g}$ chopped dry leaves of each were mixed in $200 \mathrm{ml}$ of DI water, held at $50{ }^{\circ} \mathrm{C}$ for $1 \mathrm{~h}$ and allowed to cool to room temperature. Resultant mixtures were filtered to obtain the Ficus religiosa leaf extract (FLx), Mangifera indica leaf extract (MLx), and Polyalthia longifolia leaf extract (PLx), which were further used for the GO reduction.

\subsection{Reduction of GO}

GO $\left(0.1 \mathrm{mg} \mathrm{ml}^{-1}\right)$ was mixed into $200 \mathrm{ml}$ each of FLx, MLx and PLx and ultrasonicated at $100 \mathrm{~W}$ for $2 \mathrm{~h}$ to get a homogenous dispersion of GO. Once GO was fully dispersed in the leaf extracts, the resultant solutions were directly placed into an oil bath with continuous stirring at $50{ }^{\circ} \mathrm{C}$ for $24 \mathrm{~h}$. Then, the products were washed several times with DI water and dried at $60{ }^{\circ} \mathrm{C}$ for $3 \mathrm{~h}$ in a vacuum oven. The Gns synthesized from FLx, MLx and PLx were named FGns, MGns and PGns, respectively. For comparison, another sample without any reducing agent was prepared under similar processing conditions (DI water/GO mixture $\left(0.1 \mathrm{mg} \mathrm{ml}^{-1}\right)$ stirred for $24 \mathrm{~h}$ at $50{ }^{\circ} \mathrm{C}$ followed by drying for $3 \mathrm{~h}$ at $60^{\circ} \mathrm{C}$ ).

\subsection{Fabrication of TCFs}

A spray coating technique ${ }^{35}$ was used to fabricate TCFs of synthesized MGns. MGn dispersions (10 ml) in DMF (3 and 5 $\mathrm{mg} \mathrm{ml} \mathrm{m}^{-1}$ ) were prepared by stirring for $12 \mathrm{~h}$ at $80{ }^{\circ} \mathrm{C}$. Then, the MGns/DMF dispersions were centrifuged at $3000 \mathrm{rpm}$ for $0.25 \mathrm{~h}$ and the top $5 \mathrm{ml}$ dispersion volume was sprayed onto a $25 \times 25$ $\mathrm{mm}^{2}$ quartz substrate. The coated films of 3 and $5 \mathrm{mg} \mathrm{ml}$ MGns in DMF were named GF-1 and GF-2, respectively. Before coating, the quartz substrates were ultrasonically cleaned in DI water and subsequently acetone and then dipped into piranha solution $(3: 1)$ to make the quartz surface more adhesive. An airbrush system with $0.2 \mathrm{~mm}$ nozzle diameter was used in single action mode; the distance between substrate and tip of the nozzle was kept at $12 \mathrm{~cm}$ with carrier gas $\left(\mathrm{N}_{2}\right)$ pressure of 2 bar. Spray deposition on quartz substrates was performed by toggling the $\mathrm{N}_{2}$ valve ( $2 \mathrm{ml} \mathrm{min}^{-1}$ ) and the MGns/DMF dispersion was atomized into small droplets which were carried by $\mathrm{N}_{2}$ toward the substrate preheated to $200{ }^{\circ} \mathrm{C}$. The coated films were dried in a vacuum oven for $3 \mathrm{~h}$ at $150{ }^{\circ} \mathrm{C}$. Further, thermal graphitization was done at $500{ }^{\circ} \mathrm{C}$ for $3 \mathrm{~h}$ and $900{ }^{\circ} \mathrm{C}$ for $1 \mathrm{~h}$ in $10^{-3}$ torr vacuum.

\subsection{Characterizations}

A Raman microscope from Horiba Scientific (LabRam MicroRaman spectrometer, Jobin-Yvon HR 800 UV) with He-Ne (633 $\mathrm{nm}$ ) laser was used to characterize GO, FGns, MGns and PGns. FTIR spectroscopy of GO, FGns, MGns and PGns was carried out by a PerkinElmer Spectrum. XRD patterns of graphite powder, GO and MGns were recorded with X'Pert Powder PANalytical, advanced X-ray diffractometer with $\mathrm{Cu} \mathrm{K \alpha}$. UV-vis-NIR (near infrared) spectroscopy of GO and MGns was carried out by a PerkinElmer Lambda 1050. The surface morphologies of GO and MGns were examined by FESEM (JEOL JSM-7100F), while an atomic force microscope (AFM: Agilent 5500) was employed to study the surface roughness of as-synthesized MGns. Transmission electron microscopy (TEM: FEI Titan G2 60-300) was employed to study the structure of MGns further. TGA was carried out in a $\mathrm{N}_{2}$ atmosphere at a heating rate of $10^{\circ} \mathrm{C} \mathrm{min}{ }^{-1}$ by a PerkinElmer Diamond TG/DT analyser. XPS measurements were carried out using a multifunctional XPS (ULVAC, PHI500 VersaProbe II with $\mathrm{Al} \mathrm{K} \alpha(1486.6 \mathrm{eV}) \mathrm{X}$-ray source). Electrical properties of fabricated TCFs were measured by a four-probe setup with PID-controlled oven (Scientific Equipment Roorkee, India) equipped with Keithley 6221, Keithley 2182A current and voltage sources, respectively. Optical properties were obtained in the visible range by PerkinElmer Lambda 1050. The film thickness $(t)$ and surface roughness $\left(R_{\mathrm{z}}\right)$ were measured by a BRUKER (Contour GTK0X-14-150) optical profilometer.

\section{Results and discussion}

FTIR spectra of leaf extracts (FLx, MLx and PLx) are shown in Fig. 2a. The FTIR spectrum of FLx shows the $3436 \mathrm{~cm}^{-1} \mathrm{OH}$ stretching of $\alpha$-cellulose, $1635 \mathrm{~cm}^{-1} \mathrm{C}=\mathrm{C}$ stretching of lignin, and $687 \mathrm{~cm}^{-1} \mathrm{C}-\mathrm{H}$ stretching ( $\beta$-glycosidic linkages between the monosaccharides). Similarly, the FTIR spectrum of MLx includes the mangiferin stretching vibration peak at $3399 \mathrm{~cm}^{-1}$ corresponding to the secondary O-H bond. The peak at 2903 $\mathrm{cm}^{-1}$ shows the presence of $\mathrm{C}-\mathrm{H}$ anti-symmetric stretching, 

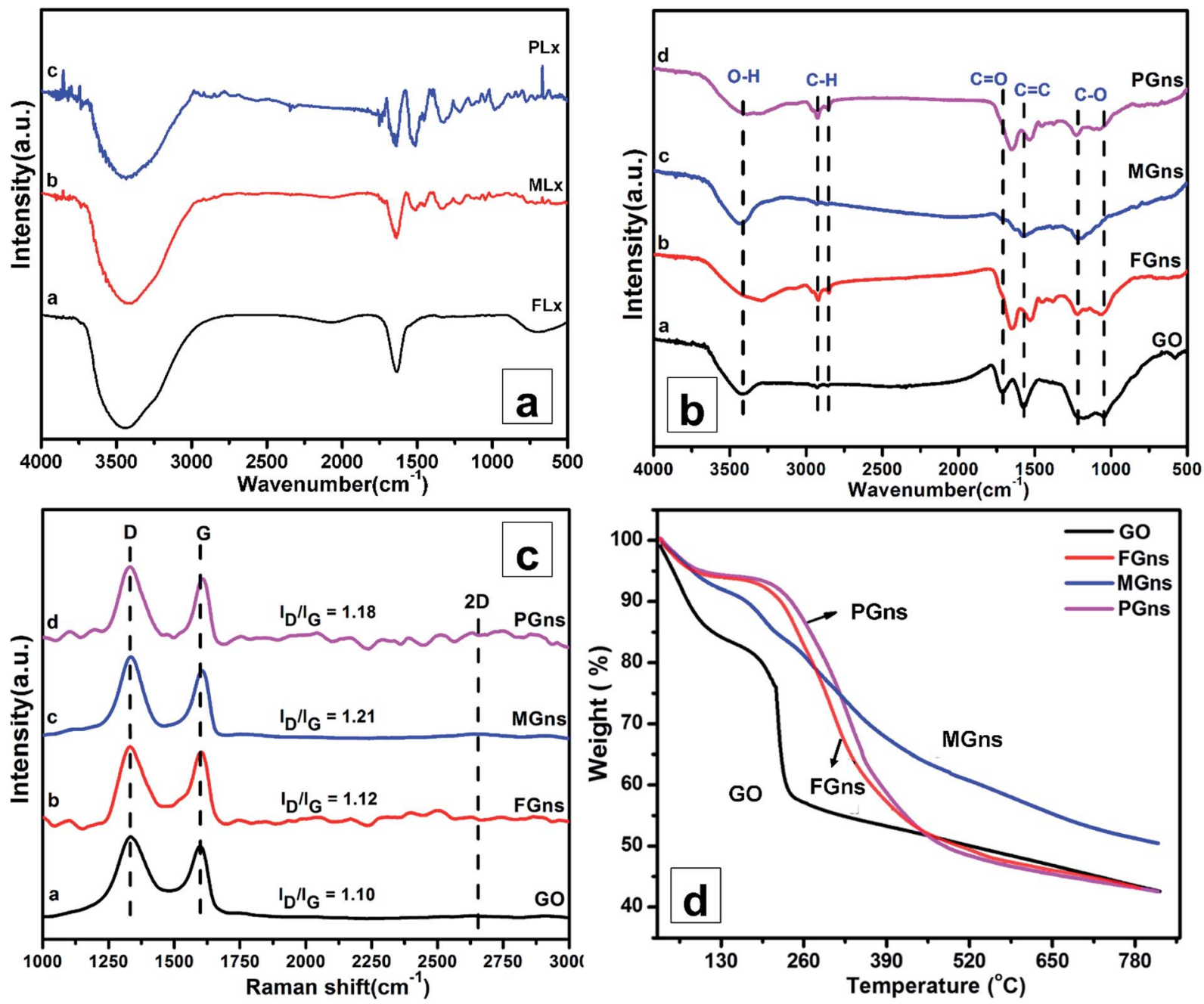

Fig. 2 FTIR spectra of (a) leaf extracts (FLx, MLx and PLx) and (b) GO and Gns (FGns, MGns and PGns). (c) Raman spectra and (d) TGA plots of GO and Gns (FGns, MGns and PGns).
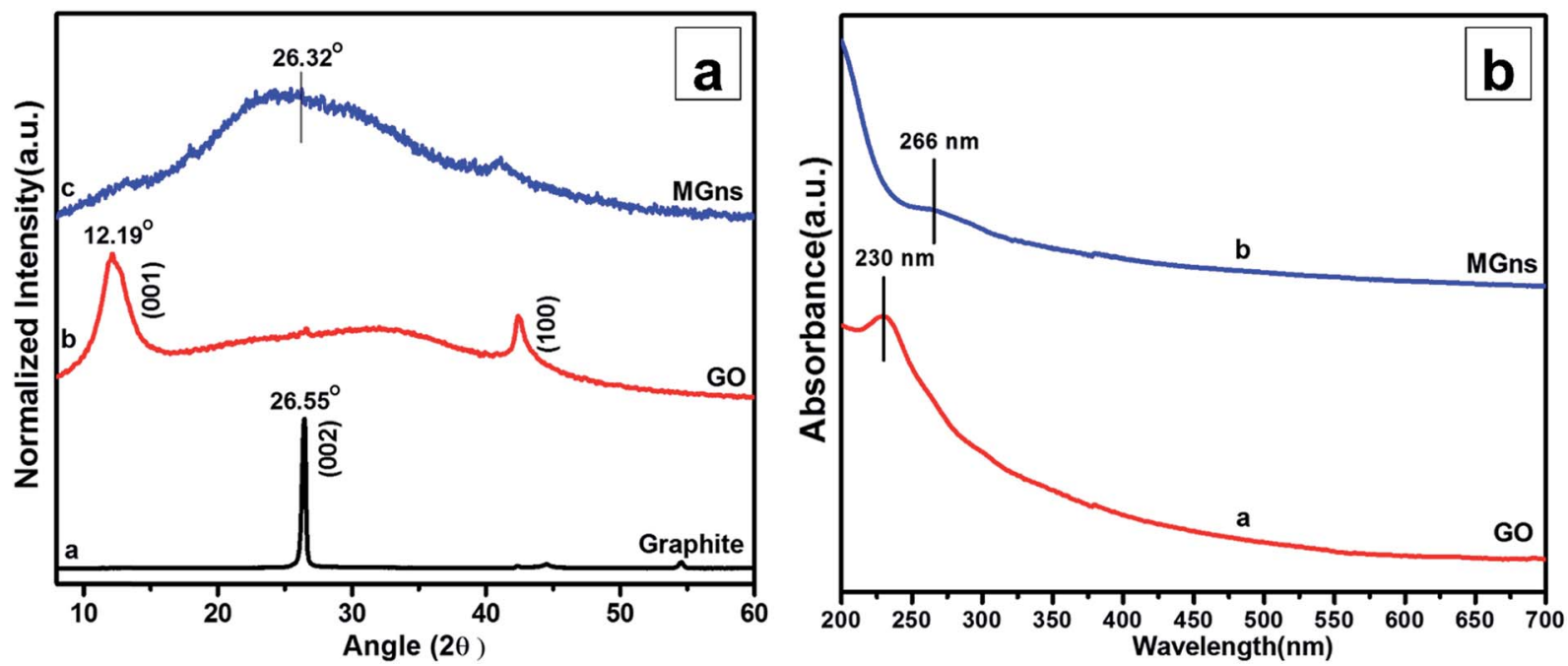

Fig. 3 (a) XRD patterns of graphite powder, GO and MGns. (b) UV-vis spectra of GO and MGns. 


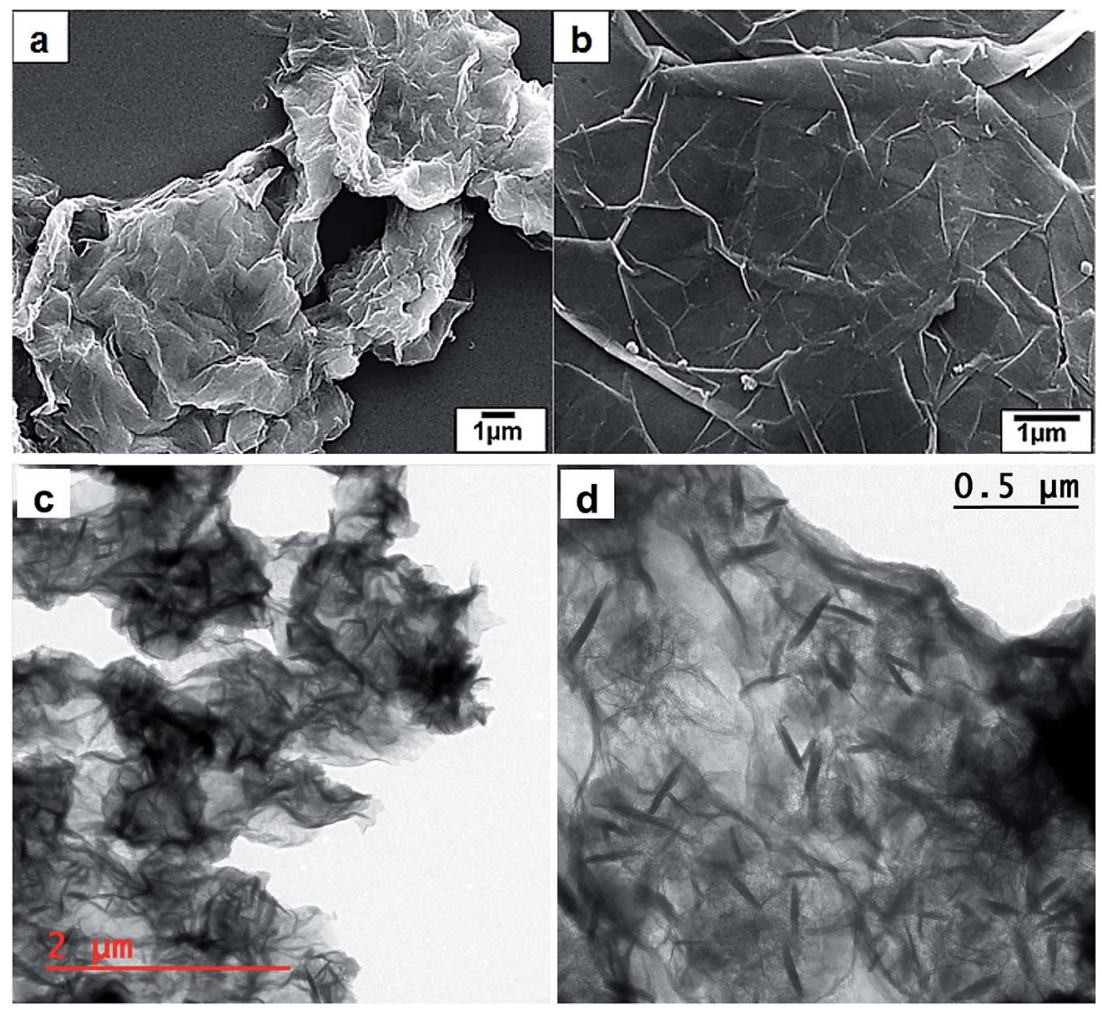

Fig. 4 FESEM images of (a) GO and (b) MGns, and ( $c$ and d) TEM images of MGns.

while the peaks at 1637,1451 and $1324 \mathrm{~cm}^{-1}$ indicate the presence of $\mathrm{C}-\mathrm{O}$ stretching, $\mathrm{CH}-\mathrm{CH}$ bending and the $\mathrm{C}-\mathrm{O}$ bond, respectively. Further, the FTIR spectrum of PLx shows the $\mathrm{O}-\mathrm{H}$ stretching vibration peak at $3435 \mathrm{~cm}^{-1}$, amide I stretching vibration peak at $1638 \mathrm{~cm}^{-1}$, amide II stretching vibration peak at $1046 \mathrm{~cm}^{-1}$ and $\mathrm{C}-\mathrm{N}$ stretching vibration of amine peak at $1046 \mathrm{~cm}^{-1}$.

Essentially, the FTIR spectra of leaf extracts reveal the presence of various functional groups associated with the constituent phytochemicals. For example, MLx, the most active reducing agent among the studied leaf extracts, contains various phenolic compounds such as acetaldehyde (1.5\%), furfural $(0.6 \%)$, 2-furanomethanol $(0.8 \%)$, phenol (3.1\%), 2,3dihydro-3,5-dihydroxy-6-methyl-4H-pyran-4-one (5.1\%), o-catechol $(1.3 \%)$, hydroquinone $(1.7 \%)$, pyrogallol $(26.9 \%)$, 2hydroxyacetophenone (1.0\%), diethyl phthalate (4.9\%) and oleic acid $(29.1 \%){ }^{36}$ Among these, pyrogallol, diethyl phthalate, hydroquinone, etc., possibly formed by the decomposition of mangiferin, are some of the known reducing agents present in the MLx. ${ }^{18,19}$ These reducing agents help in the removal of the
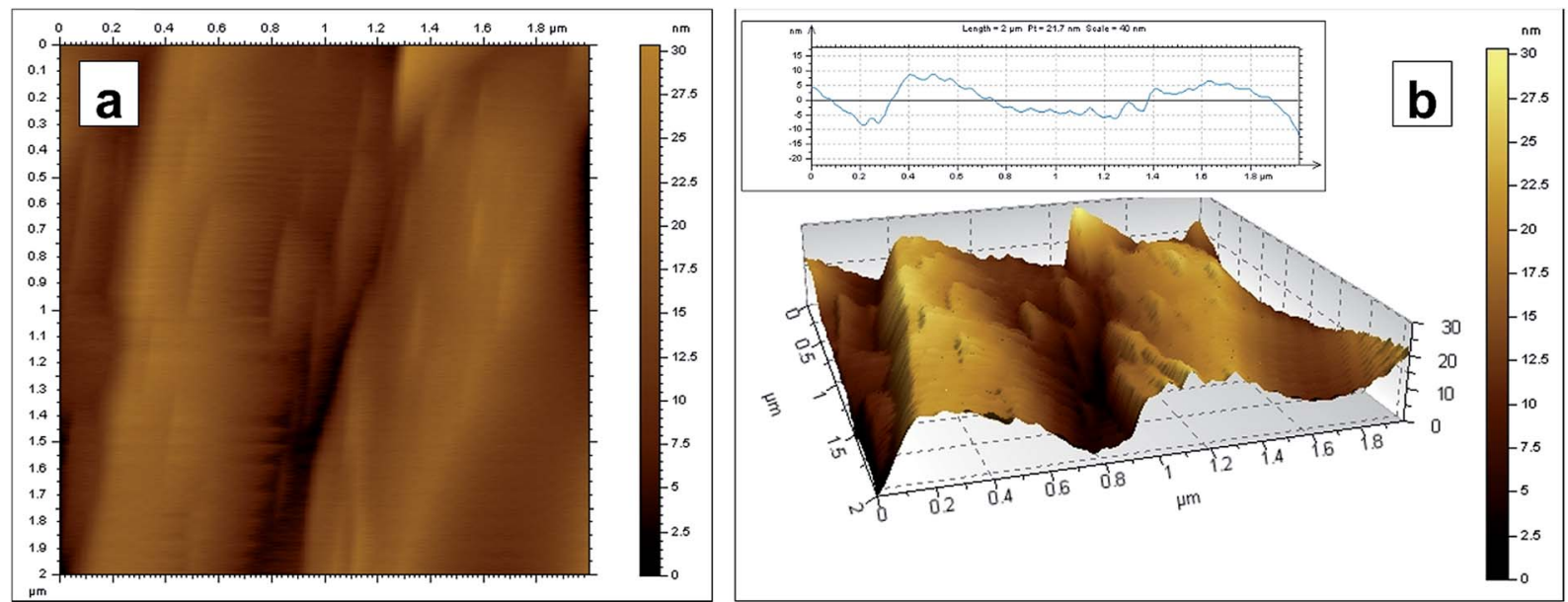

Fig. 5 (a) AFM image of MGns showing surface topography of Gns. (b) 3D view of (a). Inset of (b) shows the height profile near the middle of the AFM image (a). 

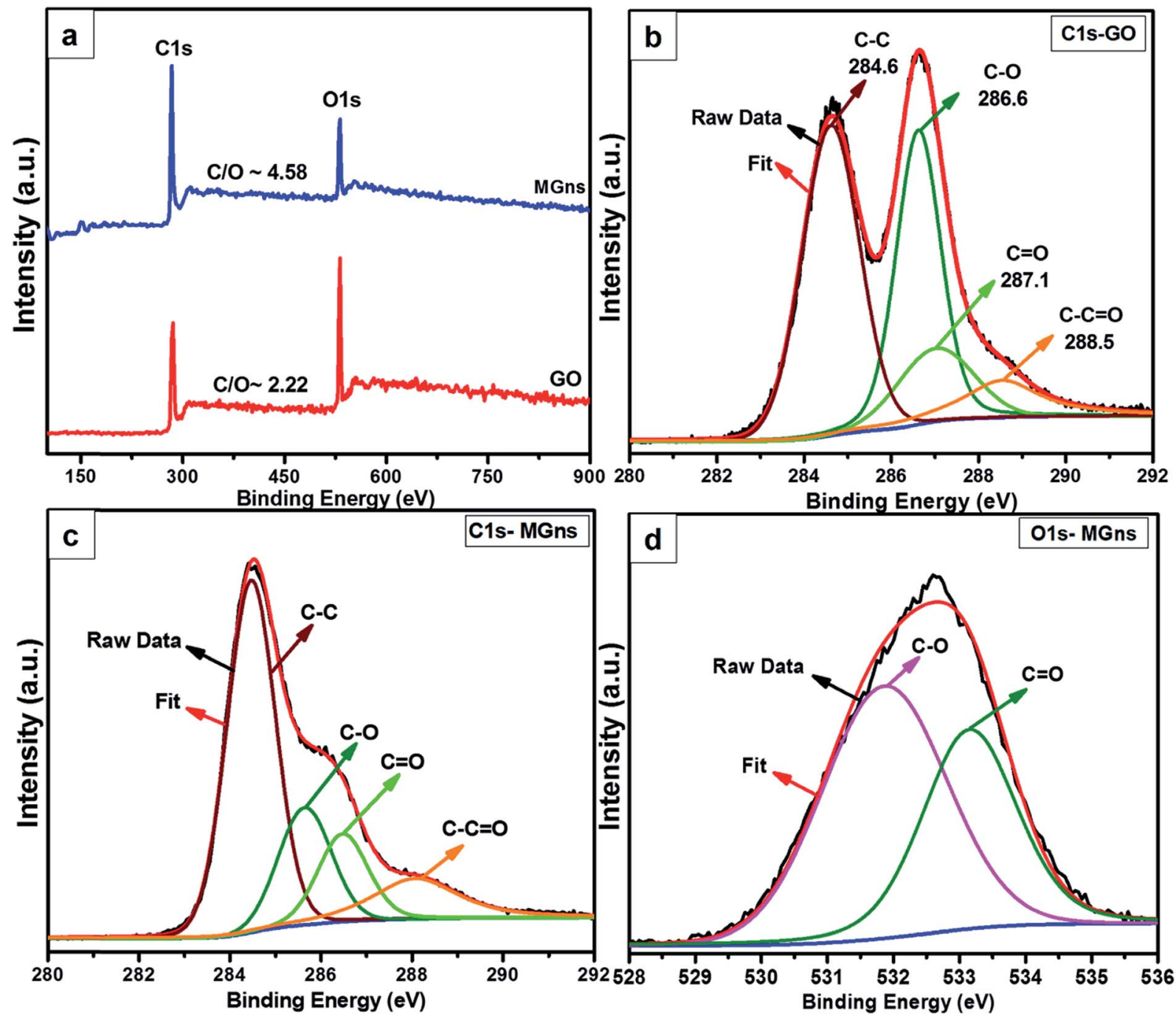

Fig. 6 XPS analysis. (a) XPS survey of GO and MGns. (b) High resolution spectra C 1s of GO. (c) High resolution spectra C 1s of MGns. (d) High resolution spectra $O$ 1s of MGns.

oxygen-containing functional groups from GO during the reduction process in order to restore electronic conjugation in the honeycomb lattice.

Fig. 2b shows the FTIR spectra of GO, and of FGns, MGns and PGns produced by the leaf extracts. The FTIR spectrum of GO shows an intense broad peak at $3424 \mathrm{~cm}^{-1}$, which is attributed to an in-plane hydroxyl group, and a peak at 1717 $\mathrm{cm}^{-1}$, which is assigned to the $\mathrm{C}=\mathrm{O}$ stretching vibration of the carboxyl groups that are situated at the edges of GO sheets. The peaks at 1576, 1233 and $1039 \mathrm{~cm}^{-1}$ are associated with the $\mathrm{C}=$ $\mathrm{C}, \mathrm{C}-\mathrm{O}$ (epoxy) and C-O (alkoxy) bonds, respectively. ${ }^{\mathbf{1 8 , 3 7}}$ The FTIR spectrum of MGns shows reduced intensity of the peaks at 2926 and $2859 \mathrm{~cm}^{-1}$, corresponding to stretching vibrations of $\mathrm{C}-\mathrm{H}$ bonds. Moreover, the peaks at 1717 and $1039 \mathrm{~cm}^{-1}$ have been suppressed after reduction, indicating the removal of most of the $\mathrm{C}-\mathrm{H}$ and $\mathrm{C}=\mathrm{O} / \mathrm{C}-\mathrm{O}$ oxygen species from GO. Meanwhile, the FTIR spectra of FGns and PGns do not show significant suppression in the peaks corresponding to the oxygencontaining functional groups, which indicates partial removal of oxygen species from GO. Hence, the MLx produces the greater loss to $\mathrm{C}-\mathrm{H}$ and $\mathrm{C}-\mathrm{O} / \mathrm{C}=\mathrm{O}$ groups, suggesting that $\mathrm{MLx}$ is the most effective green reducing agent for the preparation of Gns from GO.

Fig. 2c shows the Raman spectra of GO, FGns, MGns and PGns. The spectrum of GO exhibits two sharp intense peaks at 1332 and $1595 \mathrm{~cm}^{-1}$, which correspond to the D, G, and less intense $2 \mathrm{D}$ peak at $2629 \mathrm{~cm}^{-1}$, respectively. The $\mathrm{G}$ band at 1595 $\mathrm{cm}^{-1}$ corresponds to the in-plane vibration of $\mathrm{sp}^{2}$-bonded carbon atoms in the honeycomb lattice. The D band at 1332 $\mathrm{cm}^{-1}$ corresponds to disordered graphite; and arises due to the unsatisfied Raman fundamental selection rule of zoneboundary phonons, ${ }^{37}$ whereas the less intense peak at 2629 $\mathrm{cm}^{-1}$ corresponds to the $2 \mathrm{D}$ peak; and arises due to the second order zone boundary phonons. As compared with GO, a significant increment in the $\mathrm{D}$ to $\mathrm{G}$ band intensity ratio $\left(I_{\mathrm{D}} / I_{\mathrm{G}}\right)$ is observed in MGns and PGns. Again, no change is observed in the Raman spectrum of the GO sample processed without reducing agent (Fig. S1, ESI $\dagger$ ). This confirms the reduction of 

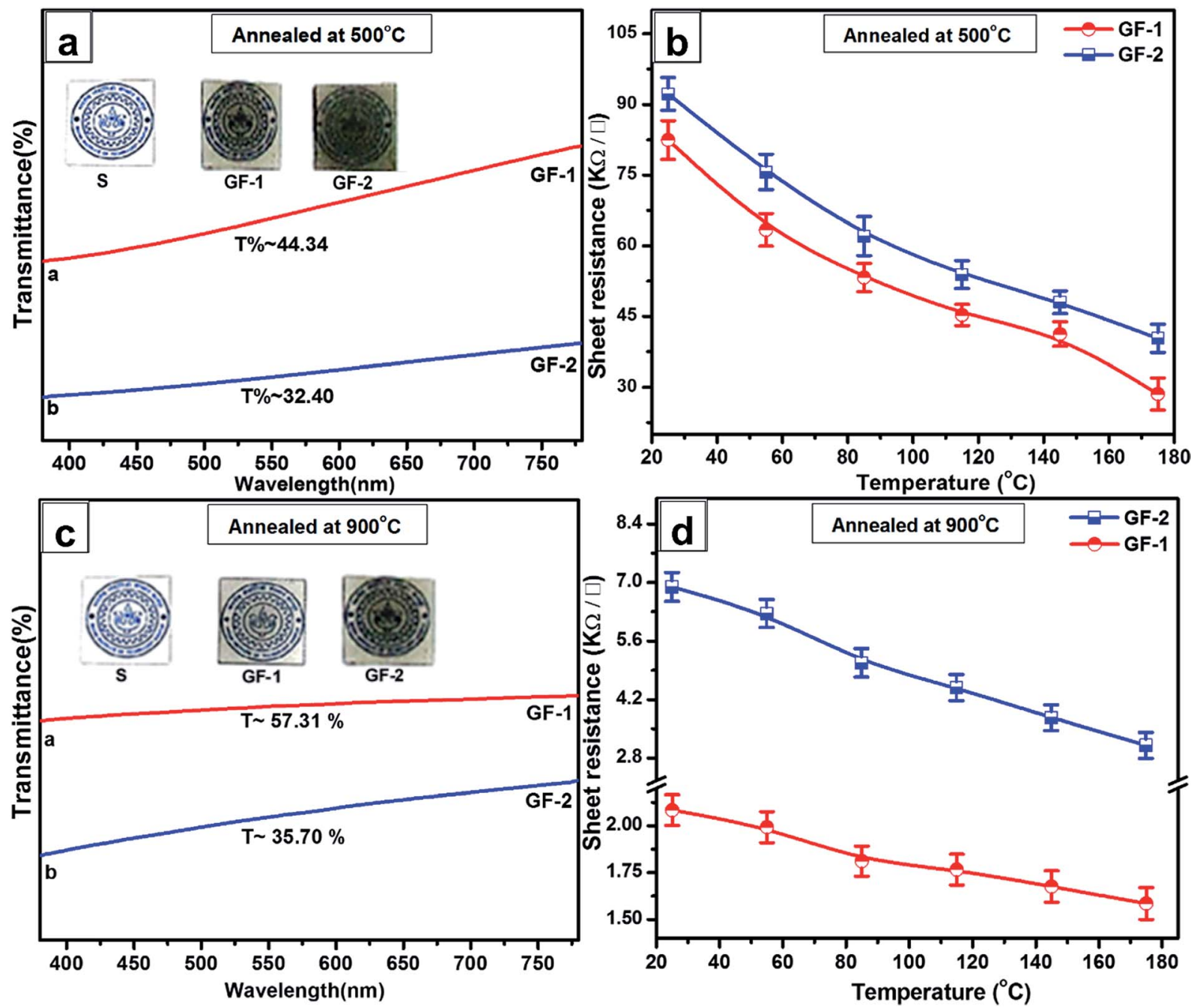

Fig. 7 Optoelectrical signatures of films. (a) Transmittance of GF-1 and GF-2 films. Inset: photographs of films. (b) Sheet resistance vs. temperature of GF-1 and GF-2 films, annealed at $500^{\circ} \mathrm{C}$. (c) Transmittance of GF-1 and GF-2 films Inset: photograph of GF-1 and GF-2 films. (d) Sheet resistance vs. temperature of GF-1 and GF-2, annealed at $900{ }^{\circ} \mathrm{C}$.

GO to be associated solely with the presence of the leaf extracts and not with the prolonged stirring in DI water at $50{ }^{\circ} \mathrm{C}$. The increased $I_{\mathrm{D}} / I_{\mathrm{G}}$ in MGns and PGns indicates the removal of oxygen functional groups from GO by the MLx and PLx, respectively. In particular, the MGn spectrum has a maximum value of $I_{\mathrm{D}} / I_{\mathrm{G}} \sim 1.21$, which confirms maximum reduction of GO by MLx. Increased $I_{\mathrm{D}} / I_{\mathrm{G}}$ ratio reveals the re-establishment of the conjugated graphene network ( $\mathrm{sp}^{2}$ carbon) and signifies that more graphene domain has been formed during reduction, which results in a decrease in the average domain size. ${ }^{11,37}$ The Tuinstra-Koenig (TK) relation: $\mathrm{La}(\mathrm{nm})=\left(2.4 \times 10^{-10}\right) \times \lambda^{4} \times$ $\left(I_{\mathrm{D}} / I_{\mathrm{G}}\right)^{-1}$ is used to calculate the crystalline domain size (La), and calculated values decrease from $34.71 \mathrm{~nm}$ for GO to 32.11 nm for MGns.

The thermal stability of as-prepared FGns, MGns and PGns has been assessed by TGA. TGA plots of GO, FGns, MGns and PGns are shown in Fig. 2d. The TGA plot of GO shows that $\sim 13.0$ wt $\%$ mass loss occurs at below $100{ }^{\circ} \mathrm{C}$, which is ascribed to the loss of water molecules adsorbed on and in the interlayer space of the GO sheets. Above $100{ }^{\circ} \mathrm{C}$, degradation starts at $167^{\circ} \mathrm{C}$, mainly due to the loss of hydroxyl, epoxy functional groups and burning of aromatic carbons; $\sim 24.8$ wt $\%$ of mass loss is observed up to $243{ }^{\circ} \mathrm{C}$. A total weight loss of $\sim 56.7 \mathrm{wt} \%$ takes place below $800{ }^{\circ} \mathrm{C}$. The TGA plot of FGns shows that the mass loss corresponding to adsorbed water (below $100{ }^{\circ} \mathrm{C}$ ) is $\sim 5.9$ wt $\%$. Above $100{ }^{\circ} \mathrm{C}$, degradation starts at $190{ }^{\circ} \mathrm{C}$, mainly due to the loss of oxygen functionalities, and mass loss of $\sim 41.6 \mathrm{wt} \%$ has occurred up to $456{ }^{\circ} \mathrm{C}$. On the other hand, PGns show higher thermal stability with a degradation onset point as high as $210{ }^{\circ} \mathrm{C}$ and mass loss of $\sim 41.0 \mathrm{wt} \%$ up to $456{ }^{\circ} \mathrm{C}$, which indicates a higher extent of reduction of oxygen functional groups from GO by PLx. In addition, the TGA plot of MGns shows that $\sim 5.6 \mathrm{wt} \%$ of mass loss occurs at below $100^{\circ} \mathrm{C}$. Above $100{ }^{\circ} \mathrm{C}$, gradual mass loss is observed mainly due to the degradation of hydroxyl and epoxy functional groups and burning of aromatic carbons. The total weight loss is observed to be $\sim 49.0 \mathrm{wt} \%$ up to $800{ }^{\circ} \mathrm{C}$. The absence of a sharp degradation onset point in MGns indicates the smallest amounts of 
oxygen functionalities as compared with the FGns and PGns samples. Owing to the superior reduction activity of MLx, the MGns have the least amounts of oxygen functional groups. Hence, further characterizations have been carried out for the MGns sample only.

The XRD patterns of graphite powder, GO and MGns shown in Fig. 3a reveal their crystalline structures. The XRD pattern of graphite powder exhibits a sharp intense peak at $2 \theta$ of $26.55^{\circ}$, corresponding to the (002) reflection of hexagonal graphite $\left(d_{\text {spacing }} \sim 3.34 \AA\right)^{12,13}$ Similarly, the XRD pattern of GO shows that the graphite crystalline peak vanishes; and arises at $2 \theta$ of $12.19^{\circ}\left(d_{\text {spacing }} \sim 7.22 \AA\right),{ }^{\mathbf{1 2 , 1 3}}$ which indicates oxidation of graphite and presence of oxygen species in the GO. GO treated under similar conditions without leaf extract exhibits no change in the XRD pattern (Fig. S2, ESI $\dagger$ ). After reduction by MLx at 50 ${ }^{\circ} \mathrm{C}$, the sharp peak (001) at $2 \theta$ of $12.19^{\circ}$ of GO disappears; and a broad peak at $2 \theta$ of $26.32\left(d_{\text {spacing }} \sim 3.36 \AA\right)$ appears. This signifies the exfoliation of the layered structure of GO and indicates the removal of oxygen functional groups from GO as well as formation of honeycomb lattice. ${ }^{38}$ Furthermore, the UVvisible spectra of GO and MGns are shown in Fig. $3 \mathrm{~b}$. The UV-vis spectrum of GO shows an absorption peak at $230 \mathrm{~nm}$ for GO, which is red shifted to $266 \mathrm{~nm}$ for MGns. The red shifting is attributed mainly to the change in electronic configuration of Gns during the process of reducing GO. Additionally, the absorption peak at $230 \mathrm{~nm}$ is ascribed to $\pi-\pi *$ transition of the aromatic $\mathrm{C}-\mathrm{C}$ ring. The red-shifted peak at $266 \mathrm{~nm}$ is ascribed to the $\mathrm{n}-\pi^{*}$ transition of $\mathrm{C}-\mathrm{O}$ bonds embedded in the MGns. ${ }^{38}$

Surface morphological analysis was carried out by FESEM. Fig. 4a depicts the microstructure of GO, revealing randomly crumpled thin sheets of oxidized graphene closely associated with each other. Ultrasonication followed by mild heattreatment in the presence of MLx reduces GO to Gns. The FESEM image in Fig. 4b shows the surface topography of the MGns, revealing the presence of multiple layers. The presence of seams on the surface is attributed to the overlapping/joining of different Gns. The TEM images of MGns shown in Fig. 4c and d reveal their crumpled structure consisting of multiple Gns entangled with each other to form a highly porous structure. The cylindrical structures in Fig. $4 \mathrm{~d}$ are possibly formed by rolling up of individual Gns. The AFM image in Fig. 5a further reveals the surface topography of MGNs. Similar to the seam structures observed in the FESEM image Fig. $4 \mathrm{~b}$, the AFM image reveals the rough surface morphology of the Gns with typical height variations ranging between $\pm 10 \mathrm{~nm}$ (inset: Fig. 5b).

XPS survey spectra of the GO and MGns shown in Fig. 6a reveal their surface chemical state. The presence of the $\mathrm{O} 1 \mathrm{~s}$ peak along with the $\mathrm{C} 1 \mathrm{~s}$ peak in the XPS survey spectrum of GO (Fig. 6a) confirms harsh oxidation of graphite to GO. The O 1s peak intensity is decreased significantly after the reduction, indicating the formation of Gns. The high resolution $\mathrm{C}$ 1s spectrum of GO, deconvoluted by using Voigt distributions and Shirley type background (Fig. 6b), consists of two intense peaks corresponding to $\mathrm{C}-\mathrm{C}$ and $\mathrm{C}-\mathrm{O}$ bonds of carbon atoms in a $2 \mathrm{D}$ planner lattice at binding energies of 284.6 and $286.6 \mathrm{eV}$, respectively, indicating a considerably high degree of oxidation. Further, weak peaks at binding energies of 287.1 and $288.9 \mathrm{eV}$ are attributed to the $\mathrm{C}=\mathrm{O}$ and $\mathrm{C}-\mathrm{C}=\mathrm{O}$ carbon bonding configurations, indicating harsh oxidation and destruction of the $\mathrm{sp}^{2}$ atomic structure of graphite..$^{39}$ The intensities of $\mathrm{C}-\mathrm{O}$, $\mathrm{C}=\mathrm{O}$ and $\mathrm{C}-\mathrm{C}=\mathrm{O}$ peaks decrease drastically when $\mathrm{GO}$ is reduced by MLx at $50{ }^{\circ} \mathrm{C}$ to produce MGns (C/O ratio increases from 2.22 to 4.58 ), which strongly indicates the restoration of $\pi$ delocalized conjugation in the honeycomb lattice (Fig. 6c). ${ }^{40}$ In addition, the high resolution $\mathrm{O}$ 1s spectrum of MGns shown in Fig. $6 \mathrm{~d}$ clearly indicates that the spectrum consists of two peaks at binding energies of 532.6 and $533.7 \mathrm{eV}$, which can respectively be assigned to $\mathrm{C}-\mathrm{O}$ and $\mathrm{C}=\mathrm{O}$ absorbed on the surface of the honeycomb network. XPS of MGns does not detect any impurity peak, confirming the formation of high quality Gns through reduction of GO by MLx. The structural

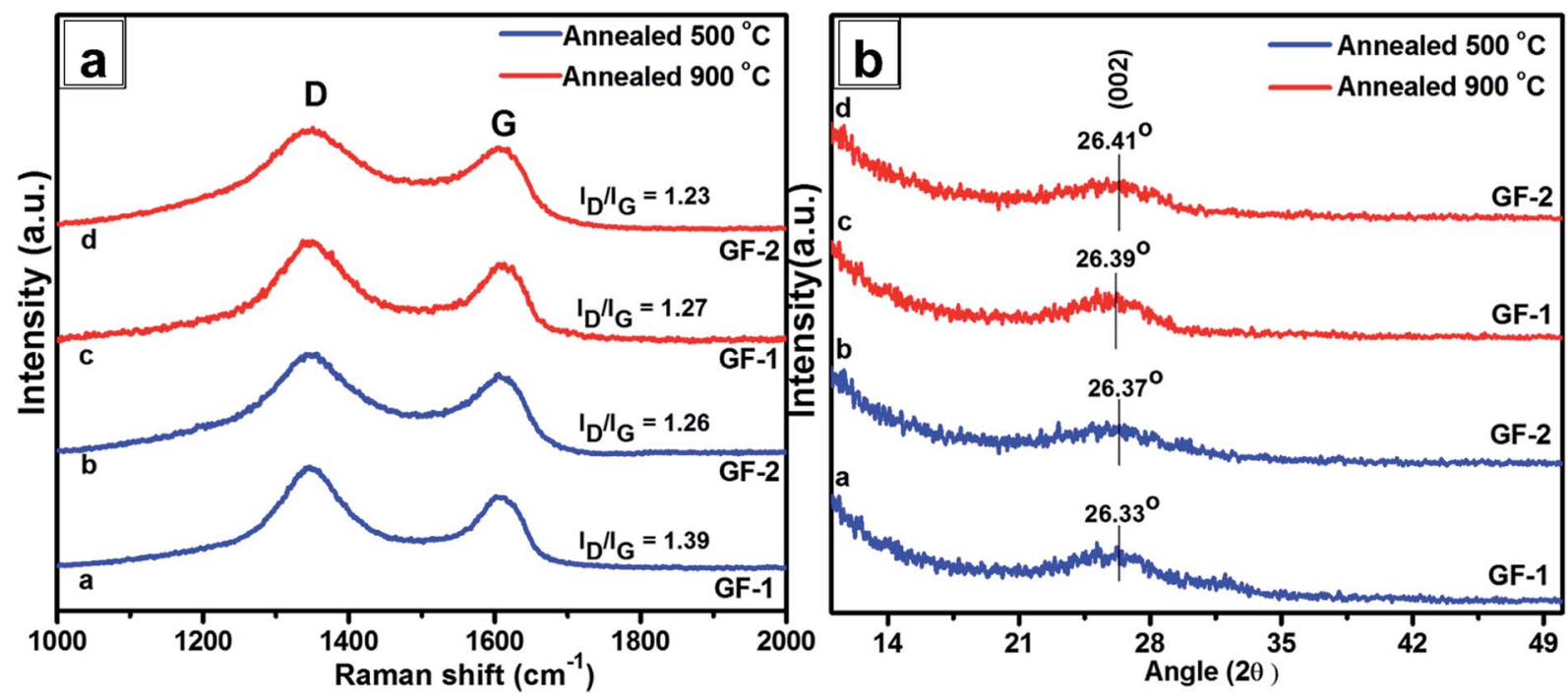

Fig. 8 Structural study of GF-1 and GF-2 films at different annealing temperature. (a) Raman analysis. (b) XRD analysis. 
Table 1 Performance evaluation of fabricated films

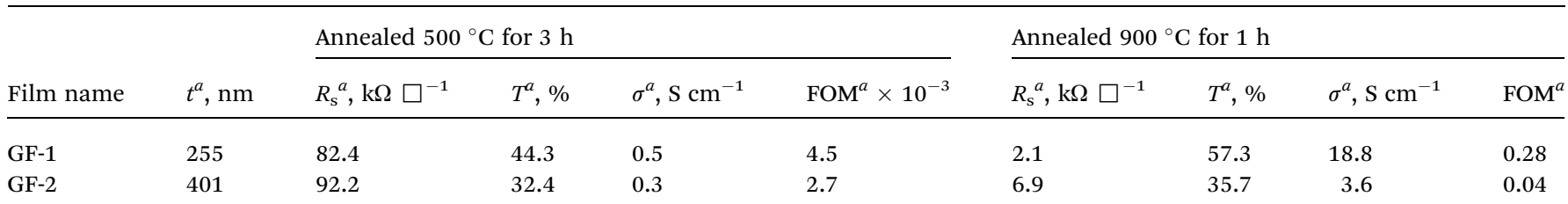

${ }^{a} t$, thickness of film; $R_{\mathrm{s}}$, sheet resistance; $T$, transmittance at $550 \mathrm{~nm} ; \sigma$, conductivity; FOM, figure of merit.

characterizations through Raman, FTIR spectroscopy, SEM, TEM and XPS confirm that MLx is an excellent green reducing agent for reduction of GO to produce Gns at large scale.

Fig. 7 shows the optoelectrical signatures of MGns films deposited on quartz substrates by spray coating. The optoelectrical properties of the coated films were measured after thermal graphitization of GF- 1 and GF-2 at $500{ }^{\circ} \mathrm{C}$ for $3 \mathrm{~h}$. The photographic images of the fabricated films are shown in the inset of Fig. 7a. It was observed that the average transmittance $\left(T_{\mathrm{av}}\right)$ values in the visible light region ( 380 to $780 \mathrm{~nm}$ ) are $\sim 45.48$ and $32.96 \%$ for GF-1 and GF-2, respectively, while the transmittance $(T)$ at $550 \mathrm{~nm}$ was found to be $\sim 44.34$ and $\sim 32.40 \%$ for the respective samples (Fig. 7a). In addition, the $R_{\mathrm{S}}$ values of the coated films were found to be $\sim 82.44$ and $92.24 \mathrm{k} \Omega \square^{-1}$ for GF1 and GF-2, respectively. Furthermore, the temperature dependent sheet resistance behavior of GF-1 and GF-2 was investigated in the temperature range from 25 to $180^{\circ} \mathrm{C}$ (Fig. 7b) by using a hot air oven model with attached Keithley currentvoltage source. The result showed that the $R_{\mathrm{S}}$ value decreased with temperature, possibly due to increased ionization states of impurities and/or increased charge carrier mobility. The decrease in $R_{\mathrm{s}}$ values of Gns film with increasing temperature is in agreement with the theoretical calculations by Fang et al. ${ }^{41}$ In addition, to investigate the effect of the thermal graphitization on optoelectrical signatures; GF-1 and GF-2 were annealed further at $900{ }^{\circ} \mathrm{C}$ for $1 \mathrm{~h}$ and it was observed that after thermal graphitization the $T_{\text {av }}$ was increased to 57.6 and $35.3 \%$ for GF-1 and GF-2, respectively (Fig. 7c). The photographic images of annealed films are shown in the inset of Fig. $7 \mathrm{c}$. Meanwhile, $T$ at $550 \mathrm{~nm}$ wavelength was found to be $\sim 57.3$ and $35.7 \%$ for GF-1 and GF-2, respectively, whereas the $R_{\mathrm{S}}$ of coated films decreased to 2.08 and $6.88 \mathrm{k} \Omega \square^{-1}$ for GF-1 and GF-2, respectively. The temperature dependent sheet resistance behavior of GF-1 and GF-2 is shown in Fig. 7d.

To determine the influence of thermal graphitization on $\mathrm{sp}^{2}$ domains, structural studies of GF-1 and GF- 2 were carried out by using Raman spectroscopy and XRD analysis. Fig. 8a shows the Raman spectra of GF-1 and GF-2 films, exhibiting prominent spectral features such as D bands at 1346 and $1348 \mathrm{~cm}^{-1}$ and $\mathrm{G}$ bands at 1610 and $1608 \mathrm{~cm}^{-1}$ for GF-1 and GF-2, respectively, when films were annealed at $500{ }^{\circ} \mathrm{C}$ for $3 \mathrm{~h}$, while the respective $I_{\mathrm{D}} / I_{\mathrm{G}}$ ratios were found to be $\sim 1.39$ and 1.26. When the annealing temperature was increased to $900{ }^{\circ} \mathrm{C}$, red shifting was observed in the D and G bands. For CF- 1 and CF-2, the D bands were observed at 1350 and $1352 \mathrm{~cm}^{-1}$, respectively, while the corresponding $\mathrm{G}$ bands lie at 1614 and $1612 \mathrm{~cm}^{-1}$. The $I_{\mathrm{D}} / I_{\mathrm{G}}$ ratios were found to be $\sim 1.27$ and 1.23 for GF-1 and GF-2, respectively, significantly lower than those for the lower annealing temperatures. This may be attributed to the removal of oxygen species from the carbon skeleton as well as the clustering of the $\mathrm{sp}^{2}$ phase and forming of a more ordered structure upon annealing. ${ }^{42}$

Furthermore, crystalline structures of the coated films were analyzed by XRD patterns, shown in Fig. 8b. For an annealing temperature of $500{ }^{\circ} \mathrm{C}$, the dominant peak in the XRD pattern was observed at $2 \theta$ of $26.33^{\circ}$ and $26.37^{\circ}$ for GF-1 and GF-2, respectively. The respective interlayer distances $\left(d_{\text {spacing }}\right)$ were calculated to be $\sim 3.367$ and $\sim 3.362 \AA$ for GF- 1 and GF-2. On the other hand, the most intense diffraction peak shifts towards higher angle with increase in annealing temperature $\left(900{ }^{\circ} \mathrm{C}\right.$ for

Table 2 Comparison of transparency and conductivity of graphene-based TCFs deposited by different processes using different reducing agents

\begin{tabular}{|c|c|c|c|c|c|c|}
\hline Method & Precursor material & Reducing agent & $\begin{array}{l}\text { Reducing agent } \\
\text { issue }\end{array}$ & $T(\%)$ & $R_{\mathrm{s}}\left(\mathrm{k} \Omega \square^{-1}\right)$ & Ref. \\
\hline L-B deposition & GO & Thermal reduction & - & 92.0 & 150.0 & 28 \\
\hline Spin coating & GO & $\mathrm{N}_{2} \mathrm{H}_{4}$ & Toxic & 80.0 & 5.0 & 30 \\
\hline Dip coating & GO & Thermal reduction & - & 70.0 & 8.0 & 31 \\
\hline Vacuum filtration & GO & $\mathrm{N}_{2} \mathrm{H}_{4}$ & Toxic & 90.0 & 890.0 & 32 \\
\hline Spin coating & GO & $\mathrm{N}_{2} \mathrm{H}_{4}$ & Toxic & 89.0 & 1.1 & 48 \\
\hline Drop cast & GO & $\mathrm{HI}$ & Toxic & 70.0 & 0.2 & 49 \\
\hline Spin coating & GO & $\mathrm{N}_{2} \mathrm{H}_{4}$ & Toxic & 78.0 & 3.1 & 50 \\
\hline Rod coating & GO & $\mathrm{Sn}$ & Not toxic & 75.0 & 6.7 & 51 \\
\hline Spray coating & GO & Leaf extract & Natural & 57.31 & 2.1 & Present work \\
\hline
\end{tabular}



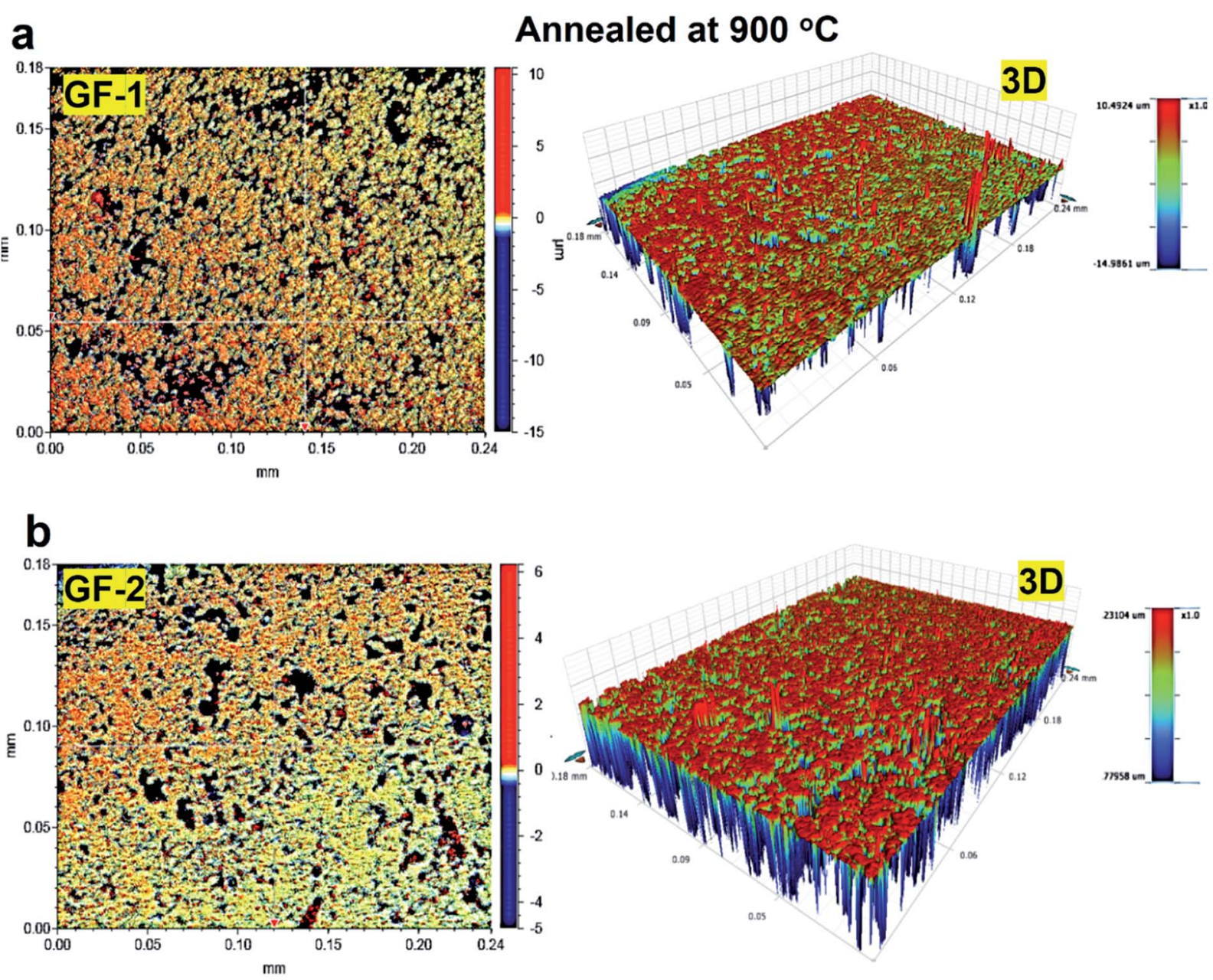

Fig. 9 Surface roughness images, 2D and 3D, of (a) GF-1 and (b) GF-2 films annealed at $900^{\circ} \mathrm{C}$.

$1 \mathrm{~h})$ and is found at $2 \theta$ of $26.39^{\circ}\left(d_{\text {spacing }} \sim 3.360 \AA\right)$ and $26.41^{\circ}$ $\left(d_{\text {spacing }} \sim 3.357 \AA\right)$ for GF-1 and GF-2, respectively. These $d_{\text {spacing }}$ values are close to the reported interlayer distance values for graphene $(\sim 3.354 \AA)$, which confirms the restoration of $\mathrm{sp}^{2}$ domains by thermal graphitization..$^{43}$ Thus, it is evident from the structural studies of films that restoration of the $\mathrm{sp}^{2}$ carbon network occurs with increase in annealing temperature and more linkages are formed between $\mathrm{sp}^{2}$ carbon networks. This indicates that the film structure shifts towards the graphene structure and the possibility of degradation of graphene film can be easily discarded. Hence, the transmittance of the film increases, $R_{\mathrm{s}}$ of the film decreases and electrical conductively increases. Electrical conductively of films ${ }^{44}$ was found to be $\sim 18.8$ and $\sim 3.6 \mathrm{~S} \mathrm{~cm}^{-1}$ for GF-1 and GF-2, respectively. To evaluate the performance of the fabricated TCFs, a figure of merit (FOM), defined as FOM $=\frac{Z_{\mathrm{O}}}{2 R_{\mathrm{S}}\left(\frac{1}{\sqrt{T}}-1\right)}$, where $Z_{\mathrm{O}}$ is the free space impedance $(377 \Omega)$, has been calculated based on $R_{\mathrm{S}}$ and $T$, and a high value of FOM signifies the better

Table 3 Comparison of transparency and conductivity of graphene-based TCFs deposited by spray coating using different reducing agents

\begin{tabular}{|c|c|c|c|c|c|c|}
\hline Spray coating & GO & $\mathrm{N}_{2} \mathrm{H}_{4}$ & Toxic & 84.0 & 2.2 & 35 \\
\hline Spray coating & GO & $\mathrm{N}_{2} \mathrm{H}_{4}$ & Toxic & 68.7 & 58.0 & 53 \\
\hline Spray coating & GO & $\mathrm{N}_{2} \mathrm{H}_{4}$ & Toxic & 80.0 & - & 54 \\
\hline Spray coating & GO & $\mathrm{N}_{2} \mathrm{H}_{4}$ & Toxic & 80.0 & 0.3 & 55 \\
\hline Spray coating & GO & Leaf extract & Natural & 57.3 & 2.1 & Present work \\
\hline
\end{tabular}


performance of TCFs, which requires high transparency and low sheet resistance. ${ }^{45}$ The performance evaluations of GF- 1 and GF-2 are tabulated in Table 1 and it is seen that GF- 1 shows better performance as TCFs than GF-2. The comparison of optoelectrical properties of graphene-based TCFs deposited by different processes are tabulated in Table 2.

Finally, surface roughness analysis of TCFs was carried out by optical profiler. It was observed that the films were coated uniformly over the quartz substrate; and the surface average roughness $\left(R_{\mathrm{z}}\right)$ was found to be $\sim 10.2$ and $\sim 21.0 \mu \mathrm{m}$ for GF-1 and GF-2, respectively (Fig. 9a and b). In addition, the thickness $(t)$ of coated films was measured; and found to be $\sim 255$ and $401 \mathrm{~nm}$ for GF-1 and GF-2, respectively. It was also observed that $R_{\mathrm{z}}$ and $t$ values increased gradually with the concentration of MGns. The comparison of transparency and conductivity of graphene-based TCFs deposited by spray coating using different reducing agents is tabulated in Table 3 . The results show that the best performing graphene-based TCFs were deposited by a simple spray coating approach from solution-processable Gns synthesized via green reduction of GO in the presence of MLx; and achieved a sheet resistance $\sim 2.1 \mathrm{k} \Omega \square^{-1}$ with a transmittance of $57.3 \%$, and had a FOM value $\sim 0.28$.

\section{Conclusions}

In summary, we have demonstrated a simple green reduction approach for GO to produce Gns using FLx, MLx and PLx. The reductive abilities of FLx, MLx and PLx were analyzed at $50{ }^{\circ} \mathrm{C}$. Raman analysis affirmed that the degree of reduction of $\mathrm{GO}$ was a maximum for MLx, with an $I_{\mathrm{D}} / I_{\mathrm{G}}$ ratio of $\sim 1.21$. FTIR analysis validated the Raman signature of maximum removal of oxygen species from GO by MLx. XPS analysis confirmed the removal of oxygen functional groups from $\mathrm{GO}$, with a maximum $\mathrm{C} / \mathrm{O}$ ratio of $\sim 4.58$. This signifies that the MLx offers a potential alternative to avoid the use of hazardous reducing agents and thus minimize environmental impact by green synthesis of Gns at large scale. Furthermore, TCFs were deposited by simple spray coating of synthesized MGns, and their optoelectrical properties were measured. The $R_{\mathrm{S}}$ and $T$ values of the best-performing GF-1 TCF were found to be $\sim 92.2 \mathrm{k} \Omega \square^{-1}$ and $\sim 44.3 \%$, respectively, for the annealing temperature of $500^{\circ} \mathrm{C}(3 \mathrm{~h})$, while for the GF- 1 annealed at $900{ }^{\circ} \mathrm{C}$ for $1 \mathrm{~h}, R_{\mathrm{S}}$ decreased significantly to $\sim 2.1 \mathrm{k} \Omega \square^{-1}$ with an increase of $T$ to $\sim 57.3 \%$.

\section{Acknowledgements}

The authors acknowledge the financial support provided by the Indian Institute of Technology Kanpur, India for carrying out this research work.

\section{References}

1 K. S. Novoselov, V. I. Falko, L. Colombo, P. R. Gellert, M. G. Schwab and K. Kim, Nature, 2012, 490, 192-200.

2 Y. Zhu, S. Murali, W. Cai, X. Li, J. W. Suk, J. R. Potts and R. S. Ruoff, Adv. Mater., 2010, 22(35), 3906-3924.
3 Y. Zhu, S. Murali, M. D. Stoller, K. J. Ganesh, W. Cai, P. J. Ferreira, A. Pirkle, R. M. Wallace, K. A. Cychosz, M. Thommes, D. Su, E. A. Stach and R. S. Ruoff, Science, 2011, 332(6037), 1537-1541.

4 Y. Zhao, X. Li, Y. Du, G. Chen, Y. Qu, J. Jiang and Y. Zhu, Nanoscale, 2014, 6, 11112-11120.

5 K. K. Kar, S. Rana and J. K. Pandey, Handbook of Polymer Nanocomposites. Processing, Performance and Application, Volume B: Carbon Nanotube Based Polymer Nanocomposites, Springer, Heidelberg, New York, Dordrecht, London, 2015.

6 Y. Chen, C. Tan, H. Zhang and L. Wang, Chem. Soc. Rev., 2015, 44, 2681-2701.

7 K. Turcheniuk, R. Boukherroub and S. Szunerits, J. Mater. Chem. B, 2015, 3, 4301-4324.

8 K. K. Kar and A. Hodzic, Developments in Nanocomposites, Research Publishing Services, Singapore, 2014.

9 S. M. Kim, J. H. Kim, K. S. Kim, Y. Hwangbo, J. H. Yoon, E. K. Lee, J. Ryu, H. J. Lee, S. Cho and S. M. Lee, Nanoscale, 2014, 6, 4728-4734.

10 P. Chamoli, M. K. Das and K. K. Kar, Graphene, 2015, 3, 5660.

11 S. Pei and H. M. Cheng, Carbon, 2012, 50(9), 3210-3228.

12 Z. Xiong, T. Gu and X. Wang, Langmuir, 2014, 30(2), 522-532.

13 Z. Xiong, C. Liao and X. Wang, J. Mater. Chem. C, 2015, 3, 6224-6231.

14 Z. Xiong, C. Liao, W. Han and X. Wang, Adv. Mater., 2015, 27(30), 4469-4475.

15 Z. Xiong, X. Yun, B. Tang and X. Wan, Carbon, 2016, 107, 548-556.

16 Z. Xiong, C. Liao and X. Wang, J. Mater. Chem. A, 2014, 2, 19141-19144.

17 M. Agharkar, S. Kochrekar, S. Hidouri and M. A. Azeez, Mater. Res. Bull., 2014, 59, 323-328.

18 S. Thakur and N. Karak, Carbon, 2012, 50(14), 5331-5339.

19 S. Barua, S. Thakur, L. Aidew, A. K. Buragohain, P. Chattopadhyay and N. Karak, RSC Adv., 2014, 4, 97779783.

20 M. Nasrollahzadeh and S. Mohammad Sajadi, RSC Adv., 2015, 5, 46240-46246.

21 C. P. Khare, Indian medicinal plants, Springer-Verlag, Berlin, Heidelberg, Germany, 2007.

22 N. Bhatla, T. Mukharjee and G. Singh, Indian J. Hist. Sci., 1984, 19(1), 37-42.

23 M. Masibo and Q. He, Compr. Rev. Food Sci. Food Saf., 2008, 7(4), 309-319.

24 C. G. Mohan, D. Mundkinajeddu, G. L. Viswanath, G. Savinay, V. Hanumantharaju, C. E. Rajendra and P. D. Halemani, Asian Pac. J. Trop. Med., 2013, 6(4), 311-314. 25 K. Ellmer, Nat. Photonics, 2012, 6, 809-817.

26 J. K. Wasseia and R. B. Kaner, Mater. Today, 2010, 13(3), 5259.

27 J. I. Paredes, S. Villar-Rodil, A. Martınez-Alonso and J. M. D. Tascon, Langmuir, 2008, 24, 10560-10564.

28 X. Li, G. Zhang, X. Bai, X. Sun, X. Wang, E. Wang and H. Dai, Nat. Nanotechnol., 2008, 3, 538-542. 
29 C. Mattevi, G. Eda, S. Agnoli, S. Miller, K. A. Mkhoyan, O. Celik, D. Mastrogiovanni, G. Granozzi, E. Garfunkel and Manish Chhowalla, Adv. Funct. Mater., 2009, 19, 2577-2583.

30 J. B. Wu, H. A. Becerril, Z. N. Bao, Z. F. Liu, Y. S. Chen and P. Peumans, Appl. Phys. Lett., 2008, 92, 263302.

31 L. Zhao, L. Zhao, Y. X. Xu, T. F. Qiu, L. J. Zhi and G. Q. Shi, Electrochim. Acta, 2009, 55, 491-497.

32 A. K. Sundramoorthy, Y. Wang, J. Wang, J. Che, Y. X. Thong, A. C. W. Lu and M. B. Chan-Park, Sci. Rep., 2015, 5, 10716.

33 H. Lux, P. Siemroth, A. Sgarlata, P. Prosposito, M. A. Schubert, M. Casalboni and S. Schrader, J. Appl. Phys., 2015, 117, 195304.

34 P. Chamoli, M. K. Das and K. K. Kar, Current Nanomaterials, 2016, 1(2), 110-116.

35 V. H. Pham, T. V. Cuong, S. H. Hur, E. W. Shin, J. S. Kim, J. S. Chung and E. J. Kim, Carbon, 2010, 48, 1945-1951.

36 D. Martínez-Bernett, A. Silva-Granados, S. N. Correa-Torres and A. Herrera, J. Phys.: Conf. Ser., 2016, 687, 012033.

37 A. C. Ferrari and D. M. Basko, Nat. Nanotechnol., 2013, 8, 235-246.

38 Y. Piao and B. Chen, RSC Adv., 2016, 6, 6171-6181.

39 S. Some, Y. Kim, Y. Yoon, H. J. Yoo, S. Lee, Y. Park and H. Lee, Sci. Rep., 2013, 3, 1929.

40 D. Yang, A. Velamakanni, G. Bozoklu, S. Park, M. Stoller, R. D. Piner, S. Stankovich, I. Jung, D. A. Field, C. A. Ventrice Jr and R. S. Ruoff, Carbon, 2009, 47, 145-152.

41 X.-Y. Fang, X.-X. Yu, H.-M. Zheng, H.-B. Jin, L. Wang and M.-S. Cao, Phys. Lett. A, 2015, 379, 2245-2251.

42 S. J. Wang, Y. Geng, Q. Zheng and J. K. Kim, Carbon, 2010, 48(6), 1815-1823.

43 H. A. Becerril, J. Mao, Z. Liu, R. M. Stoltenberg, Z. Bao and Y. Chen, ACS Nano, 2008, 2(3), 463-470.
44 S. H. Tamboli, B. S. Kim, G. Choi, H. Lee, D. Lee, U. M. Patil, J. Lim, S. B. Kulkarni, S. C. Juna and H. H. Cho, J. Mater. Chem. A, 2014, 2, 5077-5086.

45 Q. Zheng, W. H. Ip, X. Lin, N. Yousefi, K. K. Yeung, Z. Li and J. K. Kim, ACS Nano, 2011, 5(7), 6039-6051.

46 S. Y. Jeong, S. H. Kim, J. T. Han, H. J. Jeong, S. Yang and G. W. Lee, ACS Nano, 2011, 5(2), 870-878.

47 S. Mihara, T. Tsubota, N. Murakami and T. Ohno, J. Nanosci. Nanotechnol., 2012, 12(9), 6930-6934.

48 R. Karthick, M. Brindha, M. Selvaraj and S. Ramu, J. Colloid Interface Sci., 2013, 406, 69-74.

49 A. Nekahi, P. H. Marashi and D. Haghshenas, Appl. Surf. Sci., 2014, 295, 59-65.

50 X. D. Betriu, S. A. García, C. Botas, P. Álvarez, J. S. Marcos, C. Prieto, R. Menéndezb and A. de Andrés, J. Mater. Chem. C, 2013, 1, 6905-6912.

51 J. Ning, J. Wang, X. Li, T. Qiu, B. Luo, L. Hao, M. Liang, B. Wang and L. Zhi, J. Mater. Chem. A, 2014, 2, 10969-10973.

$52 \mathrm{X}$. Li, D. Zhang, C. Yang and Y. Shang, J. Nanosci. Nanotechnol., 2015, 15(12), 9500-9508.

53 H. Shi, C. Wang, Z. Sun, Y. Zhou, K. Jin and G. Yang, Sci. China: Phys., Mech. Astron., 2015, 58(1), 1-5.

54 K. Min, T. H. Han, J. Kim, J. Jung, C. Jung, S. M. Hong and C. M. Koo, J. Colloid Interface Sci., 2012, 383(1), 36-42.

55 Y. J. Lin, A. Zhamu, B. Z. Jang, S. Lee and J. C. Lin, US Pat., 20140272199 A1, 2014.

56 D. Y. Kim, S. S. Ray, J. J. Park, J. G. Lee, Y. H. Cha, S. H. Bae, J. H. Ahn, Y. C. Jung, S. M. Kim, A. L. Yarin and S. S. Yoon, Adv. Funct. Mater., 2014, 24(31), 4986-4995.

57 D. Li, M. B. Müller, S. Gilje, R. B. Kaner and G. G. Wallace, Nat. Nanotechnol., 2008, 3, 101-105. 